\title{
Reproductive efficiency in mink (Mustela vison) treated with the pesticides lindane, carbofuran and pentachlorophenol
}

\author{
A. P. Beard, A. C. McRae and N. C. Rawlings* \\ Department of Veterinary Physiological Sciences, W.C.V.M., University of Saskatchewan, \\ Saskatoon, SK S7N 5B4, Canada
}

\begin{abstract}
Mink are carnivores of agroforestry fringe habitats and are exposed to pesticides that biomagnify within the food chain. Some pesticides are thought to disrupt reproductive and endocrine functions. In Expt 1 , four groups of mink $(n=10)$ were fed either a control diet, or diets treated with lindane $\left(1 \mathrm{mg} \mathrm{kg}^{-1}\right.$ day $\left.^{-1}\right)$, carbofuran $\left(0.05 \mathrm{mg} \mathrm{kg}^{-1}\right.$ day $\left.^{-1}\right)$ or pentachlorophenol ( $1 \mathrm{mg} \mathrm{kg}^{-1}$ day $^{-1}$ ) from before breeding until weaning. Mink were mated twice, at 7-8 day intervals. The treatments had no effect on the proportion of mink accepting the first mating; however, lindane and pentachlorophenol caused a decrease in the percentage of females accepting the second mating. Lindane and pentachlorophenol caused a decrease in whelping rate, although litter size was not affected. Carbofuran had no effect on fertility. Mink that mated only once had a lower whelping rate than mink that mated twice; therefore, it could not be determined whether the decreased whelping rates were due to the lack of a second mating or to increased embryo loss. In Expt 2, two groups of mink $(n=15)$ were fed a control diet or a diet treated with lindane $\left(1 \mathrm{mg} \mathrm{kg}^{-1}\right.$ day $\left.^{-1}\right)$ from before mating until weaning. Mink were mated twice on two consecutive days. Lindane did not affect mating response at either mating. Whelping rate, but not implantation rate, was decreased by the lindane treatment. The proportion of embryos lost after implantation (implantation scars not represented by kits at whelping) was increased by the lindane treatment. In conclusion, both lindane and pentachlorophenol decreased fertility in mink, and the lindane effect was primarily a result of embryo mortality after implantation.
\end{abstract}

\section{Introduction}

A number of pesticides may pose a hazard to wild and domestic animals and humans owing to their ability to alter the normal functioning of mammalian endocrine and reproductive systems (Colborn et al., 1993). The reproductive effects of endocrine disrupting chemicals have been identified as a critical research priority in a number of recent government workshops (see Kavlock et al., 1996).

Mink are carnivores of agroforestry fringe habitats and are exposed to endocrine disrupting environmental contaminants that biomagnify within the food chain (Giesy et al., 1994; Heaton et al., 1995). Mink are seasonal breeders with induced ovulation (Hansson, 1947; Sundqvist et al., 1989). In mammals, the early embryonic period may be especially susceptible to disruption by pesticides (Mably et al., 1992; Gray et al., 1994; Guo et al., 1995) and mink may be particularly sensitive owing to their system of delayed implantation; hence mink are often used in studies of reproductive toxicology (Aulerich et al., 1973; Calabrese et al., 1992; Crum et al., 1993; Backlin and Bergman, 1995; Heaton et al., 1995).

Organochlorine pesticides are considered persistent environmental contaminants and are routinely detected in air, dust

*Reprint requests.

Received 2 January 1997. sediments, ground water and body tissues of animals and humans (Baukloh et al., 1985; Foster, 1995; Sonawane, 1995; Waite et al., 1995; Tate and Heiny, 1996; Thompson and Treble, 1996). Carbamate pesticides are less persistent than organochlorines, but are still present in air, food and ground water and are generally more toxic (Gupta, 1994). Wild animals may be particularly at risk from chronic exposure to subacute concentrations of pesticides as they live in areas of treated farmland and drink water contaminated by agricultural runoff.

In the present study, the effects of three pesticides on reproduction in mink were examined. The organochlorines used were lindane (the gamma isomer of hexachlorocyclohexane) and pentachlorophenol (PCP), and the carbamate used was carbofuran. These pesticides were chosen because they are used extensively in the prairies, and their toxic effects have been previously investigated (Spencer, 1982; Ecobichon, 1991). Lindane is an insecticide present in a variety of agricultural, medical and veterinary products that are used widely, particularly in developing countries, for the control of pests that transmit vector borne diseases (Ecobichon, 1991). Pentachlorophenol has been used extensively as a general biocide and wood preservative (Exon, 1984). Carbofuran is a broad spectrum insecticide used in agriculture and forestry throughout the world (Gupta, 1994). Previous mammalian studies of endocrine and reproductive effects of pesticides are 
limited (particularly for carnivore species) (O'Brien et al., 1993). However, studies in rodents have indicated that lindane (Sircar and Lahiri, 1989; McNutt and Harris, 1994) and pentachlorophenol (Welsh et al., 1987) alter embryonic development and oestrous behaviour (Uphouse, 1987). Carbofuran has generally been shown to have no effects on fertility or embryo development in rodents, but chronic treatment with large doses caused testicular degeneration in male beagles and hyperplasia and hydrometria in female beagles (for review, see Gupta, 1994). Other carbamate pesticides have been shown to affect fertility in sheep (Grendon et al., 1994). The doses used in the present study were based on previous studies (Spencer, 1982; Ecobichon, 1991) and our own preliminary study, and were chosen to be low enough to avoid overt toxicity but high enough to show any potential effects on the endocrine and reproductive systems.

In these studies, our specific goal was to look at the effect on fertility of lindane, pentachlorophenol and carbofuran fed to mink from before breeding until their young were weaned. A second experiment was designed to characterize the timing of the embryo loss observed in mink treated with lindane, using a revised mating protocol.

\section{Materials and Methods}

\section{Animals}

Female mink kits ( 9 months old, demibuff colour phase, $n=70$; Baldwins mink farm, Starbuck, Manitoba) were housed individually under natural conditions of daylight and temperature at $52^{\circ} \mathrm{N}$ latitude. They were fed a pelleted complete ration (Pike Lake Fox Feed, Federated Co-op Feed Mill, Saskatoon, SK) supplemented with 5-20\% chicken offal (depending on the outside temperature) mixed into a paste with water. Drinking water was provided ad libitum. Care and treatment of animals was carried out according to Canadian Council for Animal Care guidelines.

\section{Preliminary study}

Doses to be used were based on previous data for rats (Spencer, 1982; Ecobichon, 1991), which were confirmed in preliminary acute dosing studies in mink. On the basis of the results of these tests the following doses of pesticides were administered in the subsequent experiments: lindane and pentachlorophenol, $1 \mathrm{mg} \mathrm{kg}^{-1}$ body weight day ${ }^{-1}$; carbofuran, $0.05 \mathrm{mg} \mathrm{kg}^{-1}$ body weight day ${ }^{-1}$.

\section{Experiment 1}

Forty female mink were weighed and divided into four weight-matched groups $(n=10)$. The mink were fed either an untreated diet, or a diet treated with lindane (Sanex Agro, Dundos, Ontario), carbofuran (Chem Agro, Etobicoke, Ontario) or pentachlorophenol (Sigma, St Louis, MO). Individuals in each group were housed in adjacent cages with at least one empty cage between each group. The pesticides were evenly sprayed onto the pelleted ration and enough treated feed was prepared in this manner on a weekly basis (thereafter being mixed with the chicken and water each day before feeding). Treated feed was kept in darkness at $\leq 4^{\circ} \mathrm{C}$ before use. Treated or untreated feed was given throughout the study commencing 3 weeks before breeding and continuing until weaning ( 8 weeks post partum). Body weight was recorded every week during the pre-mating period and every 2 weeks during the postpartum period. Feed intake was also monitored at these times by weighing the amount of wet feed given and subtracting any feed wasted.

Mink were mated according to normal ranch practice of an initial mating, followed 7 or 8 days later by a second mating. A similar double-mating strategy has been shown to improve pregnancy rates in yearling females (Lagerkvist, 1992). Each day from 5 March to 20 March, one or two females from each group were selected randomly and mated. Single females were placed in the cage of a single breeding male $(n=10)$ and left with the male for $20 \mathrm{~min}$. If copulation had been initiated, they were left for a further $30 \mathrm{~min}$. If copulation did not take place, the females were placed with another male and if no copulation occurred on the second attempt, the female was returned to her own cage. The procedure was repeated with any unmated females on two further occasions a number of days later and, if mating still did not occur, the females were classified as non-breeding females. The mated females were mated again to a different male 7 days later. If the second mating was rejected, these females were retried 1 or 2 days later; refusal at this mating meant they were only mated once. If copulation was observed, a vaginal lavage was taken to ensure motile spermatozoa had been deposited. Males were only allowed to mate a single female on any given day.

During the whelping period the mink were checked at least twice per day to determine whether they had whelped (by listening for young in the nest box). If whelping was suspected, the litter size was counted quickly (without disturbing the nest) while the mother was kept away from the nest (since any disturbance immediately after whelping can cause cannibalization of the young). The kits were then counted and weighed every 2 weeks until weaning. At weaning (8 weeks post partum), the adult mink were separated from their litters, and sedated with ketamine (Vetlar, Vetrepharm, London, Ontario) and xylazine (Rompun, Bayvet, Etobicoke, Ontario). A blood sample was collected by cardiac puncture, and the animals were killed by an intracardial injection of T61 (Hoechst, Regina, SK). The animals were then necropsied. Samples of ovary, oviduct, uterus, pituitary, adrenal, thymus, pancreas, kidney, liver, lung, and heart were fixed in normal buffered formalin, dehydrated, and embedded in paraffin wax for sectioning, mounted and stained with haematoxylin and eosin before histopathological examination.

\section{Experiment 2}

Thirty female mink were weighed and divided into two weight-matched groups. They were fed a control or lindane (I $\mathrm{mg} \mathrm{kg}^{-1}$ day $^{-1}$ ) treated diet from 6 weeks before mating until weaning, when the adults were killed. Feed was treated in the manner outlined above.

Mink were mated using a revised protocol in an attempt to avoid the confounding effects of treatment-related changes in 
the mating response at the second mating seen in Expt 1. The protocol consisted of an initial mating, followed the next day by a second mating. Commencing on $10 \mathrm{March}$ and continuing daily until $25 \mathrm{March}$, one to nine females from each group were selected randomly and mated. Single females were placed in the cage of a single male $(n=14)$. If copulation did not take place after $20 \mathrm{~min}$, the female was tried with one other male. This procedure was repeated with any unmated females on up to four consecutive occasions at intervals of 3 days. If copulation did occur, the female was mated again to a different male the next day. If this second mating was rejected, these females were also retried with another male; refusal at this mating meant that they were only mated once. Motile spermatozoa were examined under the microscope from a vaginal lavage to confirm successful copulation. Males were only allowed to mate with a single female on any given day.

Adults and litters were treated as in Expt 1 post partum, except that litters were weaned at 10 weeks of age and weights of uterus, ovary, kidney and liver were also recorded.

\section{Hormone assays}

Blood samples were allowed to clot overnight at room temperature; serum was separated by centrifugation at $1500 \mathrm{~g}$ for $10 \mathrm{~min}$, and stored at $-20^{\circ} \mathrm{C}$ until assayed. Serum concentrations of progesterone and oestradiol were measured as described by Ravindra et al. (1994). The limits of sensitivity were $0.3 \mathrm{nmol} \mathrm{l}^{-1}$ and $3.7 \mathrm{pmol} \mathrm{l}^{-1}$, respectively. The intraassay and interassay coefficients of variation for reference sera with progesterone concentrations of 1.8 or $5.6 \mathrm{nmol} \mathrm{l}^{-1}$ were $7.2 \%$ and $9.0 \%$ or $5.3 \%$ and $8.1 \%$, respectively, and for oestradiol concentrations of 15.9 or $25.8 \mathrm{pmol}^{-1}$ were $3.0 \%$ and $8.1 \%$ or $5.1 \%$ and $12.3 \%$, respectively. Serum concentrations of cortisol were measured as described by Kingsbury and Rawlings (1993). The limit of sensitivity was $12.4 \mathrm{nmol}$ $1^{-1}$. Serum concentrations of thyroxine were measured as described by Allen et al. (1995). The limit of sensitivity was $5.0 \mathrm{nmol} \mathrm{l}^{-1}$. The intra-assay and interassay coefficients of variation for a reference serum with a cortisol concentration of $40.0 \mathrm{nmol} 1^{-1}$ were $16.0 \%$ and $13.4 \%$, and for reference sera with thyroxine concentrations of 27.0 or $51.0 \mathrm{nmol} \mathrm{l}^{-1}$ were $11.1 \%$ and $8.1 \%$ or $8.2 \%$ and $5.6 \%$, respectively.

\section{Histopathological examination}

Each tissue was examined for any potential treatment-related lesions. When a characteristic of a tissue was observed to be outside of the normal histological limits, the severity of the lesion was evaluated as follows: $0-1=$ minimal, $1-2=$ mild, $2-3=$ moderate, $3-4=$ marked. Within any of the above categories, the extent of the lesion within the tissue was scored as follows: for example $1.25=$ mild focal, $1.50=$ mild diffuse, $1.75=$ mild multifocal. Therefore, each tissue was given a score ranging from 0 to 4 .

\section{Statistical analysis}

Whelping rate is expressed as the number of mated mink that subsequently whelped. Litter size is expressed as the mean number of kits at birth, where data from only the females that produced litters are considered. The percentage embryo loss after implantation was calculated for each litter as the number of kits born subtracted from the number of implantation sites divided by the number of implantation sites. The proportion of mink in each treatment group mating, whelping, or exhibiting implantation sites was compared with the proportion in the control group by chi-squared analysis (True Epistat, Epistat services, Richardson, TX). The effects of treatment on litter size, implantation rate, embryo loss and hormone concentration were examined by Student's $t$ test (single comparisons of each treatment group with the control group; True Epistat). Proportions are expressed as percentages and all other data are presented as mean \pm SEM. The severity scores for the histopathological lesions were analysed by analysis of variance followed by Dunnett's ad hoc test (Sokal and Rohlf, 1969).

\section{Results}

\section{Experiment I}

No overt signs of toxicity were noted. During the postpartum period, mink treated with lindane appeared to be more hyper-reactive, especially when faced with the stress of handling, but this was not tested in a quantitative fashion. The pesticides did not cause any significant decrease in body weight during the premating or postpartum periods. Body weights for controls, and mink treated with lindane, carbofuran, and pentachlorophenol at the start of the study were $1139 \pm 51,1101 \pm 34,1119 \pm 50,1136 \pm 45$ g, respectively, and at weaning were $1019 \pm 48,1119 \pm 34,1023 \pm 18$, $1069 \pm 21 \mathrm{~g}$, respectively. Feed intake was similarly unaffected by the pesticide treatments, although it did vary greatly with environmental temperature changes and demands of lactation (overall mean of all time points were: control, $256 \pm 31$; lindane, $244 \pm 33$; carbofuran, $240 \pm 37$; pentachlorophenol, $249 \pm 31 \mathrm{~g}$ wet feed day ${ }^{-1}$ ).

Fertility. Fertility data are summarized (Fig. 1). The treatments had no significant effect on the proportion of mink that accepted the first mating or the date on which the mink first mated. However, the proportion of the mink mated at the first mating that subsequently accepted the second mating was significantly decreased in the groups treated with lindane $(P<0.001)$ and pentachlorophenol $(P<0.01)$. This resulted in the average last mating date being significantly earlier $(P<0.05)$ in the group treated with lindane (control, March $14.3 \pm 0.8$; lindane, March 10.1 \pm 1.4 ; carbofuran, March 13.1 \pm 1.3; pentachlorophenol, March $11.7 \pm 0.4$ ). The proportion of mated mink that whelped subsequently was reduced by the lindane $(P<0.01)$ and pentachlorophenol $(P<0.01)$ treatments. However, the proportion of mated mink that had implantation sites visible when killed at weaning and the mean number of implantation sites per mink (control, $6.75 \pm 1.22$; lindane, $6.60 \pm 1.41$; carbofuran, $5.44 \pm 0.90$; pentachlorophenol, $4.55 \pm 1.31$ ) did not differ significantly between groups. Mink that mated only once had a significantly lower whelping rate than mink mated twice (overall, 53\% versus $86 \%, P<0.001$ ). There was no significant effect of pesticide 


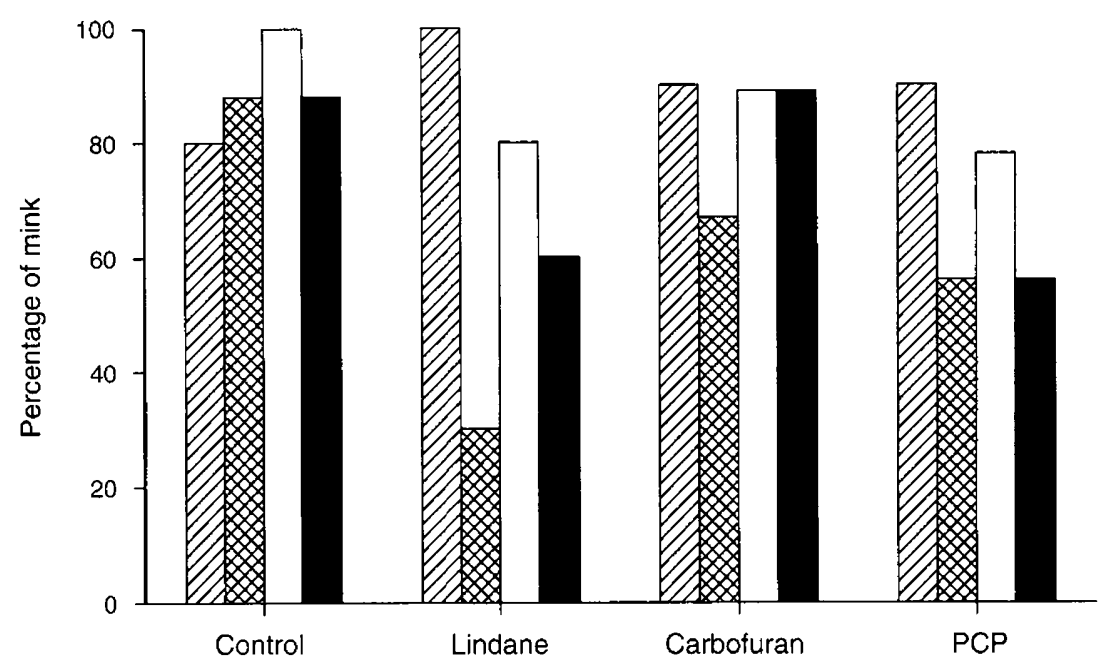

Fig. 1. Mating response, implantation rate and whelping rate in mink fed a control diet or a diet treated with lindane, carbofuran or pentachlorophenol (PCP) ( $n=10$ per group). Each

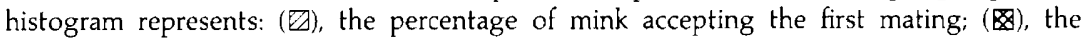
percentage of the mink mated at the first mating that subsequently accepted the second mating; ( $\square$ ), the percentage of the mated mink (mated either once or twice) with implantation sites visible at necropsy; and ( $\boldsymbol{\square})$, the percentage of mated mink that subsequently whelped.

treatment on the proportion of mink with implantation sites that whelped subsequently (control, $88 \%$; lindane, $75 \%$; carbofuran, $100 \%$; pentachlorophenol, $71 \%$ ); the mean percentage of embryos lost after implantation in each litter (control, $40.5 \pm 12.6 \%$; lindane, $61.4 \pm 14.3 \%$; carbofuran, $43.0 \pm 9.6 \%$; pentachlorophenol, $46.7 \pm 16.3 \%$ ); or the litter size of mink that whelped (control, $4.45 \pm 1.00$; lindane, $3.80 \pm 1.56$; carbofuran, $3.38 \pm 0.60$; pentachlorophenol $3.40 \pm 0.68$ ) $(P>0.1)$. Mink in the groups treated with lindane and pentachlorophenol whelped later $(P<0.05)$ than control mink (date of whelping \pm days: control, April $30.0 \pm 1.1$ : lindane, May $2.7 \pm 0.6$; carbofuran, May 1.5 \pm 0.9 ; pentachlorophenol, May $4.2 \pm 1.8$ ). The duration of pregnancy (when calculated as the number of days from the last mating until whelping) was extended $(P<0.05)$ in the group treated with lindane (control, $46.6 \pm 1.0$; lindane, $51.2 \pm 1.5$; carbofuran, $48.8 \pm 1.5$; pentachlorophenol, $52.8 \pm 2.5$ ). There were no significant differences in the proportion of male or female kits weaned or the growth rate of kits up to weaning at 8 weeks (kit weight at 2 weeks: control, $66.2 \pm 9.1 \mathrm{~g}$; lindane, $44.3 \pm 10.4 \mathrm{~g}$; carbofuran, $57.2 \pm 4.6 \mathrm{~g}$; pentachlorophenol, $64.5 \pm 3.7 \mathrm{~g}$; Kit weight at weaning: control, $504.0 \pm 46.3 \mathrm{~g}$; lindane, $482.0 \pm 76.2 \mathrm{~g}$; carbofuran, $588.9 \pm 23.2 \mathrm{~g}$; pentachlorophenol, $564.8 \pm 33.5 \mathrm{~g})$.

Endocrinology. The serum concentration of progesterone (nmol $\mathrm{l}^{-1}$ : control, $0.45 \pm 0.06$; lindane, $0.54 \pm 0.16$; carbofuran, $0.73 \pm 0.13$; pentachlorophenol, $0.45 \pm 0.13$ ) and cortisol at weaning ( $\mathrm{nmol} \mathrm{l}^{-1}$ : control, $27.1 \pm 5.4$; lindane, $56.8 \pm 18.5$; carbofuran, $57.0 \pm 13.1$; pentachlorophenol, $23.0 \pm 10.2)$ were significantly increased $(P<0.05)$ in the mink treated with carbofuran. There was no effect of pesticide treatment on oestradiol concentration (pmol $1^{-1}$ : control, $13.4 \pm 1.7$; lindane, $15.0 \pm 2.4 ;$ carbofuran, $15.0 \pm 3.6$; pentachlorophenol, $17.6 \pm 1.8$ ) or thyroxine concentration at weaning (nmol $\mathrm{l}^{-1}$ : control, $32.6 \pm 1.5$; lindane, $33.4 \pm 1.3$; carbofuran, $\quad 33.9 \pm 1.8 ; \quad$ pentachlorophenol, $\quad 31.7 \pm 1.1$ ) $(P>0.05)$.

Histopathology. Few treatment specific lesions were seen and only two uterine lesions appeared to be related to treatment. All other noted lesions did not differ significantly in severity between treated and control mink. The presence of cystic uterine glands was observed in a number of animals in all groups; however, the severity of this lesion was greatest in the mink treated with pentachlorophenol (severity scores for control and pentachlorophenol were $0.19 \pm 0.11$ and $1.33 \pm 0.47$, respectively; $P<0.05$ ). There was no incidence of mucosal inflammation in any mink treated with pesticide; however, a number of mink in the control group exhibited mild mucosal inflammation such that the severity of this lesion was significantly more pronounced in the control group $(P<0.05)$ than in each of the groups treated with pesticide (control, $0.58 \pm 0.30$; lindane, carbofuran, pentachlorophenol, $0.00 \pm 0.00)$.

\section{Experiment 2}

No overt signs of toxicity were noted. lindane did not cause any significant change in body weight during the premating period. During the postpartum period, body weight for the control mink was decreased relative to the mink treated with lindane (body weight at weaning: control, $887 \pm 31 \mathrm{~g}$; lindane, $1003 \pm 36 \mathrm{~g}$ ), probably owing to the increased metabolic cost of rearing more and larger litters.

Fertility. Fertility data are summarized (Fig. 2). The treatment had no significant effect on the proportion of mink that accepted the initial mating (control, $100 \%$; lindane, $87 \%$ ) or the 


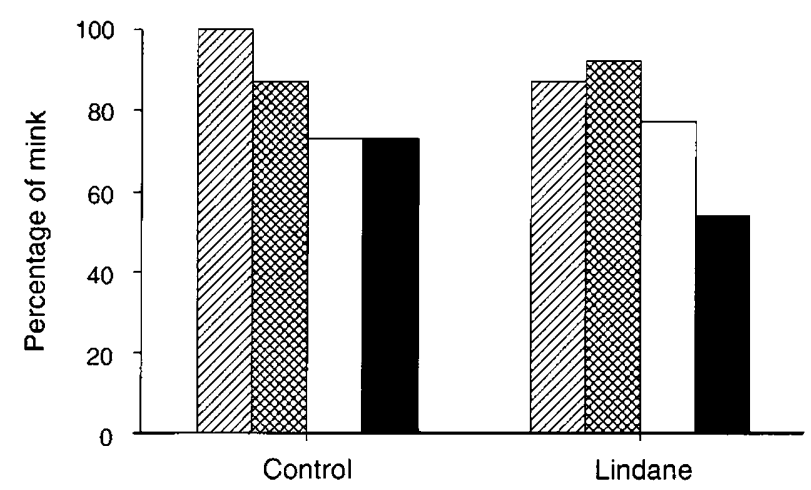

Fig. 2. Mating response, implantation rate, and whelping rate in mink fed a control diet or a diet treated with lindane ( $n=15$ per group). Each histogram represents: (包), the percentage of mink accepting the first mating; (网), the percentage of the mink mated at the first mating that subsequently accepted the second mating; $(\square)$, the percentage of the mated mink (mated either once or twice) with implantation sites visible at necropsy; and ( $\boldsymbol{\square})$, the percentage of mated mink that subsequently whelped.

date on which the first or last mating was accepted. Of the mink that mated at the first mating, the percentage of mink that accepted the second mating was also not affected by treatment (control, 87\%; lindane, 92\%). When all mink (mated and non-mated) were considered, treatment with lindane caused a significant decrease in the whelping rate (control, $73 \%$; lindane, $47 \% ; P<0.05$ ). When only the mated mink were considered, treatment with lindane also tended to cause a decrease in whelping rate (control, $73 \%$; lindane, $54 \%$; $P<0.1$ ). However, the proportion of mated mink with implantation sites (control, $73 \%$; lindane, $77 \%$ ) and the number of implantation sites per mink (control, 5.07 \pm 1.08 ; lindane, $3.69 \pm 0.98$ ) were not affected by treatment with lindane $(P>0.1)$. The proportion of mink with implantation sites that whelped subsequently was reduced by treatment with lindane (control, 100\%; lindane, $70 \%: P<0.05$ ). The proportion of embryos lost after implantation in each litter (implantation scars not represented by kits at whelping) was significantly greater in the group treated with lindane compared with the control group (control, $30.5 \pm 8.3 \%$; lindane, $64.9 \pm 10.0 \% ; P<0.01$ ). The increased incidence of embryo loss was mostly accounted for by the loss of complete litters in three of the mink treated with lindane. If the results from these three mink were removed from the data set, the rate of embryo loss was similar in both groups (control, $30.5 \pm 8.3 \%$; lindane, $40.6 \pm 9.4 \% ; P>0.1$ ). The mean litter size of mink that whelped was not significantly reduced by lindane (control, $4.73 \pm 0.98$; lindane, $3.29 \pm 0.64 ; P>0.1$ ). Mink in the group treated with lindane tended to whelp later than control mink (control, May 4.6 \pm 1.5; lindane, May $8.7 \pm 2.7 ; P<0.1$ ). However, duration of gestation was not affected by the lindane treatment (control, 52.2 \pm 1.8; lindane, 54.9 \pm 3.2 days; $P>0.1$ ). There were no significant differences in the proportion of male or female kits weaned or the body weight of kits at 2 weeks (control, $72 \pm 4.8 \mathrm{~g}$; lindane, $82 \pm 4.2 \mathrm{~g}$ ) and 10 weeks (control, $760 \pm 91 \mathrm{~g}$; lindane, $704 \pm 4 \mathrm{I} \mathrm{g}$ ) of age.

Endocrinology. Serum concentration of cortisol (nmol l-1: control, $61.5 \pm 9.8$; lindane, $23.5 \pm 3.8$ ) was significantly lower
$(P<0.01)$ in the mink treated with lindane. Concentrations of oestradiol (pmol ${ }^{-1}$ : control, $11.8 \pm 1.8$; lindane, $7.71 \pm 1.8$ ) progesterone (nmol $\mathrm{l}^{-1}$ : control, $0.45 \pm 0.06$; lindane, $0.57 \pm 0.19$ ) and thyroxine (nmol $\mathrm{l}^{-1}$ : control, $27.5 \pm 1.3$; lindane, 31.6 \pm 2.1$)$ did not differ between groups $(P>0.05)$.

Histopathology. Only one uterine lesion appeared to be related to treatment. All other noted lesions did not differ statistically in severity between treatment and control groups. The most significant finding was that haemosiderosis of the uterus appeared to be inhibited in the treated animals (severity score for control $=0.82 \pm 0.27$; lindane $=$ $0.02 \pm 0.02 ; P<0.01)$. The severity of haemosiderosis was most marked in the control group mink which carried large litters to term.

\section{Discussion}

Experiment 1 demonstrated that exposure to both lindane and pentachlorophenol had a detrimental effect on fertility; however, it was not clear whether the lower whelping rates were the result of a direct effect on embryo survival or an indirect effect of the lack of a second mating on embryo loss. Although neither the lower implantation rate nor the lower survival of embryos after implantation in the mink treated with lindane and pentachlorophenol were statistically significant compared with control mink, the combined effect of these decreases contributed to the reduced whelping rate. The decrease in the number of mink that accepted a second mating I week after the first mating appeared to be the result of an unwillingness to copulate on the part of the females when placed with a male, since when the males were exposed subsequently to an untreated female (not involved in the current experiment) copulation took place. The second mating is used routinely in normal ranch practice since it has been demonstrated to improve whelping rates (Lagerkvist, 1992). Therefore, a missed second mating would be expected to reduce whelping rates and it was clear from the results of the current study that mink that mated only once had a significantly lower whelping rate than mink that mated twice. Experiment 2 showed that when the mating response was equivalent in lindane and control mink, there was still a decreased whelping rate. Again, implantation rate was unaffected by treatment and, therefore, the majority of embryo loss was deemed to have occurred after implantation. Similar results have been observed in mink exposed to polychlorinated biphenyls (Backlin and Bergman, 1995).

This study is the first to show that lindane causes increased embryo loss in mink; however, the mechanism by which lindane has this effect is unclear. Previous studies in rabbits (Paimer et al., 1978a) and mice (Sircar and Lahiri, 1989) using short-term treatments with high doses of lindane at various stages of pregnancy showed a marked negative effect on fertility. However, when progesterone and oestradiol were given with lindane during early pregnancy, both implantation and fetal development were normal (progesterone alone had no effect; Sircar and Lahiri, 1989). Lindane decreased the rate of steroidogenesis in mice by inhibition of cholesterol side chain cleavage (Sircar and Lahiri, 1990) and has been shown to 
decrease progesterone concentrations (Srivastava and Raizada, 1993). Lindane has also been shown to be anti-oestrogenic, in that it blocks the response of oestrogen-dependent tissues to oestradiol (Chadwick et al., 1988; Cooper et al., 1989; Laws et al., 1994). However, in rats, lindane does not appear to exert its effect by binding to the oestrogen receptor (Uphouse and Williams, 1989). Lindane has also been shown to have a direct degenerative affect on mouse (Alm et al., 1994) and bovine (Alm et al., 1996) embryos in culture. Hassoun and Stohs (1995) indicated that certain fetotoxic effects of lindane may be due to superoxide production induced by oxidative stress. The decreased incidence of haemosiderosis in mink treated with lindane in the present study may have been a symptom, rather than a cause, of the decreased whelping rate in the second experiment. Alternatively, it may have been a direct effect of lindane, suggesting an inhibition of the monocytemacrophage system or an alteration in endothelial integrity, which may play a role in the increased incidence of embryo loss. It is unlikely that the increased incidence of embryo loss observed merely represents a symptom of general pesticide toxicity, since no significant lesions related to the treatments were observed in the histological examination and no detrimental effects on feed intake or body weight were recorded.

In the present study, whelping rate in mink was also decreased by pentachlorophenol. In rats, pentachlorophenol has been shown to increase the incidence of fetal reabsorption and to cause an increase in fetal abnormalities when given during organogenesis and at doses at least tenfold higher than those given in the present study (Schwetz et al., 1974; Exon, 1984; Welsh ef al., 1987). Exon (1984) suggested that the major mode of action of pentachlorophenol was its ability to uncouple oxidative phosphorylation. The increased severity of cystic uterine glands may have contributed to the increased incidence of embryo loss in the mink treated with pentachlorophenol. Cystic uterine glands may be associated with uterine infection and this could indicate an immunosuppressive activity of pentachlorophenol on the uterus. In the present study, carbofuran had no effect on reproductive function in mink, in agreement with work in rats (Barnett et al., 1980).

The doses of lindane and pentachlorophenol used in the present study were lower than those used in some previous studies in which no effects were observed on embryo loss in rats (Palmer et al., 1978b; Welsh et al., 1987). Mink may be particularly susceptible to lindane and pentachlorophenol owing to their extended period of embryonic diapause. During the period of embryonic diapause, circulating oestradiol concentrations remain high and further ovulations can be induced (Lagerkvist ef al., 1992). In mink, an increase in prolactin terminates embryonic diapause by initiating progesterone production (Murphy et al., 1981). The increased incidence of embryo loss in mink treated with lindane may be the result of inadequate concentrations of steroid hormone or altered responsiveness to ovarian steroid hormones. The progesterone concentration may be critical since there appears to be a decline in uterine progesterone receptors immediately after implantation in carnivores (Mead and Eroschenko, 1995). McRae (1994) concluded that inadequate progesterone secretion or excessive oestradiol secretion may be important causes of preimplantation embryo loss in ranched mink. Unfortunately, we were unable to collect blood samples at the time of implantation since the stress of disturbance involved in this procedure was likely to have caused even further embryo loss (Tauson, 1988). No effect of lindane on serum oestradiol or progesterone concentrations was apparent at the time of weaning in this study; however, steroid concentrations were very low at weaning. The later whelping date in mink treated with lindane and pentachlorophenol in this study mirrors the effect seen in rats where lindane is known to decrease uterine contractions by an inhibitory effect on the gap junctions essential for successful parturition (Kamrin et al., 1994). This effect appears to be mediated by an increase in arachidonic acid (Criswell and Loch-Caruso, 1994).

In the present study, lindane and pentachlorophenol also caused a reduction in the number of mink accepting a second mating 7 or 8 days after the initial mating. In untreated mink, after the initial mating, a new cohort of ovarian follicles develops over the next few days (Douglas et al., 1994). The follicles secrete oestradiol, increasing sexual receptivity, and the female accepts a second mating 7-8 days later and ovulates a second cohort of follicles (Hansson, 1947). As a significant proportion of the mink treated with lindane and pentachlorophenol did not accept the second mating, we can speculate that follicle growth was disrupted after the initial mating had induced ovulation, leading to a decline in oestradiol production. Higher doses of lindane have been shown to inhibit cell proliferation and DNA synthesis in an in vitro system involving cultured bovine granulosa cells (Tiemann et al., 1996), and relatively low doses of lindane can reduce ovulation rates in rabbits (Lindenau et al., 1994). The initial mating was not affected by the treatment with lindane or pentachlorophenol, possibly because the follicles present at this mating had developed before the start of treatment. Lordosis and proceptive behaviour were also reduced in rats administered high doses of lindane during pro-oestrus (Uphouse, 1987) or dioestrus (Uphouse and Williams, 1989), probably as a result of direct neurobehavioural effects since such doses cause overt convulsions. The behaviours seen in mink treated with lindane that failed to mate at the second attempted breeding (rearing, vocalization, and aggression towards the male) were similar to those seen in rats treated with lindane and to those seen when an anoestrous female mink is placed with an active male. There do not appear to be any previous studies showing an effect of pentachlorophenol on receptivity and oestrous behaviour in mammals. Despite the fact that the decreased second mating response in the group treated with lindane did not totally account for the decreased whelping rate, it is still of interest because a decrease in libido in a wild population could have serious effects at the population level. Mink are likely to be exposed to much lower doses of lindane and pentachlorophenol in their natural habitat; however wild populations may be exposed to a mixture of pesticides with possible additive and synergistic effects. Tissue concentrations of pesticides in mink fed the same doses of lindane and pentachlorophenol during a longer term study (A. Beard, unpublished) and in calves given similar treatment (Hughes et al., 1985) were $1-5 \mathrm{mg} \mathrm{kg}^{-1}$. These concentrations are generally 10-1000 times higher than those measured in wild animals (Franson et al., 1974; Krynski et al., 1982; Falandysz and Kannan, 1992). 
Serum cortisol concentration was increased in mink treated with carbofuran in Expt 1 and reduced in mink treated with lindane in Expt 2; however, single time point measurements of cortisol are relatively unreliable compared with frequent sampling as cortisol secretion is episodic (Goodman, 1994) and may vary in response to stress. Studies have detected increased plasma concentrations of corticosterone in rats exposed in utero and neonatally to low doses of carbofuran, but not in rats given high doses (Cranmer et al., 1978). Lindane treatment in rats has been shown to affect adrenal function adversely, leading to a reduction in plasma glucocorticoid concentration (Lahiri and Sircar, 1991); however, in rabbits, lindane treatment causes an increase in cortisol secretion (Anand et al., 1990).

In conclusion, this study showed that exposure of mink to the organochlorine pesticide lindane caused an increase in the number of embryos lost after implantation. The mechanism of this effect is unclear but may involve a disruption in oestrogendependent changes normally associated with pregnancy as is seen in mice treated with lindane (Sircar and Lahiri, 1989). Lindane and pentachlorophenol also decreased the number of females accepting a second mating when this was attempted I week after the initial mating. Pentachlorophenol also caused a decrease in whelping rate, but it is unclear whether this is a direct effect on embryo loss or a result of the reduction in mating response. Carbofuran did not appear to have any effect on reproduction. Pregnancy in mink appears to be particularly sensitive to the ingestion of low concentrations of pesticides and this may be due to particular characteristics of gestation in mink, such as the extended period of embryonic diapause. Environmental contamination with organochlorine pesticides may pose a risk to wild populations of mink owing to disruptive effects of these substances on fertility.

The authors thank S. J. Cook for technical assistance throughout the study, E. Rasmussen for care and management of the mink, R. B. Miller for the histopathological evaluations, and P. Bartlewski, R. K. Chandolia, A. Honaramooz and D. Waldbillig for help with the mink necropsies. This research was funded by the Canadian Network of Toxicology Centres and the Canadian Mink Breeders Association.

\section{References}

Allen AL, Doige CE, Haas SD, Card CE and Fretz PB (1995) Concentrations of triiodothyronine and thyroxine in equine fetal serum during gestation Biology and Reproduction Monograph I 49-52

Alm H, Tiemann U and Torner H (1994) Influence of environmental pollutants on development of mouse embryos in vitro. Journal of Reproduction and Fertility Abstract Series 4 Abstract 66

Alm H, Torner H and Tiemann U (1996) Influence of organochlorine pesticides on maturation and further development of bovine oocytes in vitro. Proceedings of the International Conference on Animal Production, Sydney pp 14-20

Anand M, Gulati A, Gopal K, Gupta GS, Khanna RN, Ray PK and Chandra SV (1990) Hypertension and myocarditis in rabbits exposed to hexachlorocyclohexane and endosulfan Veterinary and Human Toxicology 32 (6) 521-523

Aulerich RJ, Ringer RK and Iwamoto S (1973) Reproductive failure and mortality in mink fed on Great Lakes fish Journal of Reproduction and Fertility $19365-376$

Backlin B-M and Bergman A (1995) Histopathology of postpartum placental sites in mink (Mustela vison) exposed to polychlorinated biphenyls or fractions thereof APMIS 103 843-854

Barnett JB, Spyker Cranmer JM, Avery DL and Hoberman AM (1980) Immunocompetence over the lifespan of mice exposed in utero to carbofuran or diazinon: I. Changes in serum immunoglobulin concentrations joumal of Environmental Pathology and Toxicology 4 (5-6) 53-63
Baukloh V, Bohnet HG, Trapp M, Heeschen W, Feichtinger W and Kemeter P (1985) Biocides in human follicular fluid Annals New York Academy of Sciences 240-250

Calabrese EJ, Aulerich RJ and Padgett GA (1992) Mink as a predictive model in toxicology Drug Metabolism Review 24 (4) 559-578

Chadwick RW, Cooper RL, Chang J, Rehnberg GL and McElroy WK (1988) Possible antiestrogenic activity of lindane in female rats Journal of Biochemistry and Toxicology 3 147-158

Colborn T, vom Saal FS and Soto AM (1993) Developmental effects of endocrine-disrupting chemicals in wildlife and humans Environmental Health Perspectives 101 (5) 378-384

Cooper RL, Chadwick RW, Rehnberg GL, Goldman JM, Booth KC, Hein JF and McElroy WK (1989) Effect of lindane on hormonal control of reproductive function in the female rat Toxicology and Applied Pharmacology 99 384-394

Cranmer JS, Avery DL, Grady RR and Kitay JI (1978) Postnatal endocrine dysfunction resulting from prenatal exposure to carbofuran, diazinon or chlordane Journal of Environmental Pathology and Toxicology 2 (2) 357-369

Criswell KA and Loch-Caruso R (1994) Lindane-induced elimination of gap junctional communication in rat uterine myocytes is mediated by an arachidonic acid-sensitive cAMP-independent mechanism Biology of Reproduction $\mathbf{5 0}$ (1)

Crum JA, Burisan SJ, Aulerich RJ, Polin D and Braselton WE (1993) The reproductive effects of dietary heptachlor in mink (Mustela vison) Archives of Environmental Contamination and Toxicology 24 156-164

Douglas DA, Pierson RA and Murphy BD (1994) Ovarian follicular development in mink (Mustela vison) Journal of Reproduction and Fertility 100 583-590

Ecobichon DJ (1991) Toxic effects of pesticides. In Cassareft and Doull's Toxicology 4th edn pp 565-622 Eds MO Amdur, J Doull and CD Claystone. Toronto, Ontario

Exon I (1984) A review of chlorinated phenols Veterinary and Human Toxicology 26(6) 508-520

Falandysz J and Kannan K (1992) Organochlorine pesticide and polychlorinated biphenyl residues in slaughtered and game animal fats from the northern part of Poland Z Lebensm Unters Forsch 195 17-21

Foster WG (1995) The reproductive toxicology of Great Lakes contaminants Environmental Health Perspectives 103 (9) 63-69

Franson JC, Dahm PA and Wing LD (1974) Chlorinated hydrocarbon insecticide residues in adipose, liver, and brain samples from lowa mink Bulletin of Environmental Contamination and Toxicology 11 379-385

Giesy JP, Vergrugge DA, Othout RA, Bowerman WW, Mora MA, Jones PD, Newsted JL, Vandervoort C, Heaton SN, Aulerich RJ, Bursian SJ, Ludwig JP, Dawson GA, Kubiak TJ, Best, DA and Tillitt DE (1994) Contaminants in fishes from Great Lakes-influenced sections and above dams of three Michigan rivers. II. Implications for health of mink Archives of Environmental Contamination and Toxicology 27 213-223

Goodman HM (1994) Basic Medical Endocrinology Lippincott-Rover Publishers, New York

Gray LE, Jr, Ostby J, Monosson E and Kelce WR (1994) Alterations of sex differentiation in male rats following perinatal exposure to low doses of the antiandrogenic pesticide vinclozolin (V) Biology of Reproduction 50 (Supplement 1) 101

Grendon J, Frost F and Baum L (1994) Chronic health effects among sheep and humans surviving an aldicarb poisoning incident Veterinary and Human Toxicology 36 (3) 218-223

Guo YL, Lambert GH and Hsu CC (1995) Growth abnormalities in the population exposed in utero and early postnatally to polychlorinated biphenyls and dibenzofurans Environmental Health Perspectives 103 (6) 117-122

Gupta RC (1994) Carbofuran toxicity Journal of Toxicology and Environmental Health 43 383-418

Hansson A (1947) The physiology of reproduction in mink (Mustela vison, Schreb.) with special reference to delayed implantation Acta Zoologica 28 $1-136$

Hassoun EA and Stohs SJ (1995) Comparative studies on oxidative stress as a mechanism for the fetotoxicity of TCDD, endrin and lindane in C57BL/6J and DBA/2J mice Teratology 51 (3) 186

Heaton SN, Bursian SJ, Giesy JP, Tillitt DE, Render JA, Jones PD, Verbrugge DA, Kubiak TJ and Aulerich RJ (1995) Dietary exposure of mink to carp from Saginaw Bay, Michigan. 1. Effects on reproduction and survival, and the potential risks to wild mink populations Archives of Environmental Contamination and Toxicology 28 334-343 
Hughes BJ, Forsell J, Sleight SD, Kuo C and Shull LR (1985) Assessment of pentachlorophenol toxicity in newborn calves: clinicopathology and tissue residues Joumal of Animal Science 61 1587-1603

Kamrin MA, Carney EW, Chou K, Cummings A, Dostal LA, Harris C, Henck JW, Loch-Caruso R and Miller RK (1994) Female reproductive and developmental toxicology: overview and current approaches Toxicology Letters 74 99-119

Kavlock RJ, Daston GP, DeRosa C, Fenner-Crisp P, Gray LE, Kaattari S, Lucier G, Luster M, Mac MJ, Maczka C, Miller R, Moore J, Rolland R, Scott G, Sheehan DM, Sinks T and Tilson HA (1996) Research needs for the risk assessment of health and environmental effects of endocrine disruptors: a report of the US EPA-sponsored workshop Environmental Health Perspectives 104 (4) 715-740

Kingsbury DL and Rawlings NC (1993) Effect of exposure to a boar on circulating concentrations of LH, FSH, cortisol and oestradiol in prepubertal gilts Journal of Reproduction and Fertility 98 245-250

Krynski A, Kaluzinski J, Delong A, Dutkiewicz M and Labudzki L (1982) Polychloride and carbamate insecticide contamination of roe deer inhabiting fields and forests Acta Theriologica 27 489-497

Lagerkvist G (1992) Mating systems and endocrinology of oestrus in mink (Mustela vison). In Reproduction in Carnivorous Fur Bearing Animals pp 51-71 Eds A-H Tauson and M Valtonen. Jordbrugsterlaget, Copenhagen

Lagerkvist G, Einarsson EJ, Forsberg M and Gustafsson H (1992) Profiles of oestradiol-17 $\beta$ and progesterone and follicular development during the reproductive season in mink (Mustela vison) Journal of Reproduction and Fertility $9411-21$

Lahiri P and Sircar S (1991) Suppression of adrenocortical function in female mice by lindane (gamma-HCH) Toxicology 66 (1) 75-79

Laws SC, Carey SA, Hart DW and Cooper RL (1994) Lindane does not alter the estrogen receptor or the estrogen-dependent induction of progesterone receptors in sexually immature or ovariectomized adult rats Toxicology 92 127-142

Lindenau A, Fischer B, Selier P and Beier HM (1994) Effects of persistent chlorinated hydrocarbons on reproductive tissues in female rabbits Human Reproduction 9(5) 772-780

McNutt TL and Harris C (1994) Lindane embryotoxicity and differential alteration of cysteine and glutathione levels in rat embryos and visceral yolk sacs Reproductive Toxicology 8 (4) 351-362

McRae AC (1994) Ovarian hormones secretion and embryo development during early pregnancy in mink and ferrets Animal Reproduction Science 34 315-326

Mably TA, Moore RW and Peterson RE (1992) In utero and lactational exposure of male rats to 2,3,7,8-tetrachlorodibenzo-p-dioxin Toxicology and Applied Pharmacology 114 97-107

Mead RA and Eroschenko VP (1995) Changes in uterine estrogen and progesterone receptors during delayed implantation and early implantation in the spotted skunk Biology of Reproduction 53 827-833

Murphy BD, Concannon PW, Travis HF and Hansel W (1981) Prolactin: the hypophyseal factor that terminates embryonic diapause in mink Biology of Reproduction 25 487-491

O'Brien DJ, Kaneene JB and Poppenga RH (1993) The use of mammals as sentinels for human exposure to toxic contaminants in the environment Environmental Health Perspectives 99 351-368
Palmer AK, Bottomley AM, Worden AN, Frohberg H and Bauer A (1978a) Effect of lindane on pregnancy in the rabbit and rat Toxicology 9 230-247

Palmer AK, Cozen DD, Spicer EJF and Worden AN (1978b) Effects of lindane upon reproductive function in a 3 -generation study in rats Toxicology $\mathbf{1 0}$ 45-54

Ravindra JP, Rawlings NC, Evans ACO and Adams GP (1994) Ultrasonographic study of ovarian follicular dynamics in ewes during the oestrous cycle Journal of Reproduction and Fertility 101 501-509

Schwetz BA, Keeler PA and Gehring PJ (1974) The effect of purified and commercial grade pentachlorophenol on rat embryonal and fetal development Toxicology and Applied Pharmacology 28 151-161

Sircar S and Lahiri P (1989) Lindane ( $\mathrm{g}-\mathrm{HCH}$ ) causes reproductive failure and fetotoxicity in mice Toxicology 59 171-177

Sircar S and Lahiri P (1990) Effect of lindane on mitochondrial side-chain cleavage of cholesterol in mice Toxicology 61(1) 41-46

Sokal KJ and Rohlf FJ (1969) Biometry WH Freeman and Co., San Francisco

Sonawane BR (1995) Chemical contaminants in human milk: an overview Environmental Health Perspectives 103 (6) 197-199

Spencer EY (1982) Guide to the Chemicals used in Crop Production 7th edn. Agriculture Canada Research Branch, Research Centre, London, Ontario

Srivastava MK and Raizada RB (1993) Prenatal effects of technical hexachlorocylcohexane in mice Journal of Toxicology and Environmental Health $\mathbf{4 0}$ 105-115

Sundqvist C, Amador AG and Bartke A (1989) Reproduction and fertility in the mink (Mustela vison) Journal of Reproduction and Fertility 85 413-441

Tate CM and Heiny JS (1996) Organochlorine compounds in bed sediment and fish tissue in the South Platte River Basin, USA, 1992-1993 Archives of Environmental Contamination and Toxicology 30 62-78

Tauson AH (1988) Effect of flushing in plasma progesterone and plasma estradiol throughout gestation in mink Proceedings of the 4th International Science Congress on Fur-bearing Animal Production. Toronto pp 31-42

Thompson TS and Treble RG (1996) Pentachlorophenol levels in human urine Environmental Contamination and Toxicology 56 520-526

Tiemann U, Pöhland R and Schneider F (1996) Influence of organochlorine pesticides on physiological potency of cultured granulosa cells from bovine preovulatory follicles Theriogenology 46 253-265

Uphouse L (1987) Decreased rodent sexual receptivity after lindane Toxicology Letters 39 7-14

Uphouse L and Williams J (1989) Diestrous treatment with lindane disrupts the female rat reproductive cycle Toxicology Letters 48 2I-28

Waite DT, Grover R, Westcott ND, Irvine DG, Kerr LA and Sommerstad H (1995) Atmospheric deposition of pesticides in a small southern Saskatchewan watershed Environmental Toxicology and Chemistry 14 (7) 1171-1175

Welsh JJ, Collins TFX, Black TN, Graham SL and O'Donnell MW, Jr (1987) Teratogenic potential of purified pentachlorophenol and pentachloroanisole in subchronically exposed Sprague-Dawley rats Food Chemistry and Toxicology 241309 